\title{
Biyogüvenlik için Gerekli Bazı Faktörler Bakımından Malatya illi Süt Sığırcılığı İşletmelerinin Değerlendirilmesi
}

\author{
Ibrahim ŞEKER', Abdurrahman KÖSEMAN ${ }^{2}$, Durhasan MUNDAN ${ }^{3}$
}

1. Fırat Üniversitesi, Veteriner Fakültesi, Zootekni Anabilim Dalı, Elazı̆̆, TÜRKiYE.

2. İnönü Üniversitesi, Akçadağ M.Y.O., Bitkisel ve Hayvansal Üretim Bölümü, Malatya, TÜRKiYE.

3. Harran Üniversitesi, Veteriner Fakültesi, Zootekni Anabilim Dalı, Şanlıurfa, TÜRKiYE.

\begin{tabular}{|c|c|c|}
\hline $\begin{array}{c}\text { Geliş Tarihi/Received } \\
\text { 26.02.2016 }\end{array}$ & $\begin{array}{c}\text { Kabul Tarihi/Accepted } \\
\text { 03.02.2017 }\end{array}$ & $\begin{array}{c}\text { Yayın Tarihi/Published } \\
\text { 30.04.2017 }\end{array}$ \\
\hline $\begin{array}{l}\text { Öz: Bu araştırma, biyogüvenlik is } \\
\text { sığır işletmelerinin durumunu o } \\
\text { seçilen } 78 \text { adet sığırclık işletmes } \\
\text { olarak yüz yüze anket uygulanm } \\
\text { tahliyesi için ızgaralı kanal siste } \\
\text { Otomatik suluk ve kaşıma fırçası } \\
\text { günlük temizlik uygulanan ve yet } \\
\text { olarak belirlenmiştir. Sonuç ola } \\
\text { sağlayacak birtakım düzenlemel } \\
\text { olumsuzlukların giderilmesi için, } \\
\text { verilmesi, yürürlükteki mevzuat } \\
\text { yapılması gerektiği kanaatine var }\end{array}$ & $\begin{array}{l}\text { törler bakımından Mala } \\
\text { nacıyla yapılmıştır. Bu } \\
\text { ıe değerlendirmeler yap } \\
\text { nada, işletme içerisinde } \\
\text { nelerin oranları sırasıyl } \\
\text { elerin oranı ise sırasıyla } \\
\text { yapılan işletme oranları } \\
\text { süt sığırılığı işletmeler } \\
\text { re ihtiyaç olduğu tespit } \\
\text { n yönetici ve personele } \\
\text { uygulanması, işletmele }\end{array}$ & $\begin{array}{l}\text { a̧̧ ve üzeri kapasiteye sahip sütçü } \\
\text { örnekleme metodu kullanılarak } \\
\text { iplerine gönüllülük esasına dayalı } \\
\text { enlik kamerası ve ahırlarda gübre } \\
\text { ve \%9.0 olarak tespit edilmiştir. } \\
\text { olarak saptanmıştır. Araştırmada, } \\
\text { r bazında sırasıyla \%89.7 ve \%92.3 } \\
\text { ğin yeterli düzeye ulaştırılmasını } \\
\text { n gerçekleştirilmesi ve belirlenen } \\
\text { bilgilendirme çalışmalarına önem } \\
\text { lenetimlerinin daha aktif şekilde }\end{array}$ \\
\hline
\end{tabular}

Anahtar Kelimeler: Biyogüvenlik, Eğitim, Hijyen, Sütçü işletme.

\section{The Determination of Dairy Farms in Terms of Some Factors Affecting Biosecurity in Malatya}

\begin{abstract}
This research was conducted to determine some factors that affect the biosecurity of dairy farms which have 50 and over head cows in Malatya. For this purpose, investigations and evaluations were held in farms and face to face interviews were applied with 78 breeders selected by using the random sampling method. It is found that the ratio of the existence of managing buildings, security camera in the business, and grid channel system for manner transferring in shelters are respectively $16.7 \%, 17.9 \%$ and $\% 9.0 \%$. The usage of automatic drinkers and grooming brushes are calculated respectively $43.6 \%$ and $57.7 \%$. It is estimated that the ratio of the sanitation of shelters is $89.7 \%$ and adequate vantilation is $92.3 \%$. In conclusion, it is determined that some applications and changes are required to maintain a sufficient level of biosecurity. To consider and resolve the problems, it was concluded that training and informing all the staff and the managers in earnest, applying the administrative sanctions effectively as well as controlling and inspecting more actively was necessary.
\end{abstract}

Keywords: Biosecurity, Dairy farms, Hygiene, Training.

\footnotetext{
Abdurrahman KÖSEMAN

İnönü Üniversitesi, Akçadağ M.Y.O., Bitkisel ve Hayvansal Üretim Bölümü, Malatya, TÜRKiYE.

e-posta: abdurrahman.koseman@inonu.edu.tr
} 


\section{GiRiş}

B

iyogüvenlik; hastalıkların etkisini en aza indirerek hayvan sağlığını iyileştirmeyi, bu yolla yardımcı tedavi maliyetlerini azaltmayı ve verimliliği en yüksek düzeye çıkararak işletme karlılığını artırmayı sağlayan uygulamalardır. Bu uygulamalar doğrudan veya dolaylı yollarla hayvanlarda hastalığa neden olabilecek etkenlere karşı bir koruma sağlar. İşletmelerde etkili bir biyogüvenlik sisteminin uygulanması, hastalıkların yayılmasını sağlayan biyolojik organizmaların işletmelere giriş ve hareket serbestliğini enaz seviyeye indirmektedir (1)

Sütçü işletmelerde uygulanacak sağlık önlemleri; süt üretimi, üreme performansı ve sürü varlığında sağlayacağı artışların yanında, hastalıklar nedeniyle oluşan ekonomik kayıpların azaltılması için oldukça önemlidir (2)

Hayvancılık faaliyetlerinin gerek sürdürülebilir biçimde yapılması, gerekse hayvan başına yüksek verim sağlanması için bireysel hayvan tedavilerinin ötesinde sürü odaklı biçimde hareket edilmesi, çiftlik uygulamaları ve yönetiminin gözden geçirilerek bulaşıcı hastalıklardan uzak bir işletme yapısı oluşturulması önem arz etmektedir (3). Malatya'daki sütçü işletmelerde yapılan bir araştırmada, işletmelerdeki buzağı ölümlerinin oranı \%55.8 olarak bildirilmiştir (4).

Malatya, Doğu Anadolu Bölgesi'nde tarımsal ekonomi ve hayvancılık bakımından önemli bir ildir. İldeki sığır varlığı 130.375 baş olup, ilçeler arasında Battalgazi (13.215 baş), Doğanşehir (13.710 baş), Akçadağ (11.500 baş), Yeşilyurt (6.945 baş) ve Merkez (29.868 baş) ön sıralarda yer almaktadır. Malatya'daki toplam sığırcılık işletmelerinin sayısı ise 25.199 adet olup, 1-5 baş arası büyüklüğe sahip işletmelerin sayısı 19.407 adet ve 26+ olanlar ise 756 adettir. Illdeki kombine işletme sayısı 3.293 adet ve sadece süt sığırcılığı yapan işletme sayısı ise 20.564 adettir. Ancak, Malatya ilinin Kasım-2012'de Büyükşehir olması nedeniyle ilçe ve merkez sınırları değişmiş, Merkez'de yeralan hayvanlar mevcut araştırmanın planlandığı ve yürütüldüğü sırada sistem değişikliği nedeniyle Yeşilyurt ve Battalgazi ilçelerine aktarılmıştır $(5,6)$.

Ekonomik ve sürdürülebilir hayvancılığın önemli bir unsuru olan biyogüvenlik düzeylerinin tespitine yönelik yapılan araştırmalar, diğer faydaları yanında, ilgili paydaşların dikkatlerinin bu noktaya çekilmesine katkı sağlamaktadır. Tarafımızdan yapılan araştırma ve literatür incelemelerinde farklı perspektiften yapılmış bir araştırma (7) dışında, Malatya ilinde sığır yetiştiriciliği yapılan işletmelerde biyogüvenlikle ilgili gerçekleştirilmiş herhangi bir çalışmaya ulaşılamamıştır.

Bu araştırmada, Malatya ilinde faaliyet yürüten sütçü sığırcılık işletmelerinin mevcut durumlarının biyogüvenlik uygulamaları kapsamında gerekli bazı yapısal, donanımsal, yönetimsel ve personel faktörleri bakımından değerlendirilmesi amaçlanmıştır.

\section{MATERYAL ve METOT}

Araştırmada, 2015 yılında Malatya ilinde yarı entansif yetiştiricilik yapılan 78 adet süt sığırcılığı işletmesinde biyogüvenlik konusuna ilişkin, işletme sahipleriyle gönüllülük esasına dayalı olarak yüz yüze yapılan anket uygulamalarından elde edilen veriler kullanılmıştır.

Bilimsel araştırmalarda popülasyonu temsil edecek örnek büyüklüğü arttıkça örneğin populasyonu temsil edebilme gücü de artmakatdır. Ancak, bu örnek büyüklüğüne bağlı olarak araştırma 
için gerekli zaman ve maliyetin de önemli olduğu unutulmamalıdır $(8,9)$. Bu çalışmadaki örnek büyüklüğü, ildeki 26 baş ve üzeri süt sığırcılığı yapan işletmelerin sayısından hareketle, populasyonu temsil için \%10'una ulaşılması hedeflenerek, bahsi geçen koşullar $(8,9)$ göz önüne alınarak ve benzer çalışmalardaki (10-12) örnek büyüklükleri de incelenerek en az 75 işletme olarak belirlenmiştir. Araştırmada belirlenen örnekleme büyüklüğü ile ildeki 50 baş üzeri işletmelerin oluşturduğu populasyonun \%10'undan daha fazlasının örneğe dahil edilmesi sağlanmıştır.

Çalışmaya 50 baş ve üzerinde süt sığırı bulunan ve yarı açık ahır tipine sahip ve yarı entansif yetiştiricilik yapılan işletmeler dahil edilmiş olup, ilk önce en fazla hayvan ve işletme sayısına sahip ilçeler belirlenmiştir. Bu işletmelerle ilgili bilgiler Gıda Tarım ve Hayvancılık Bakanlığı Malatya î Müdürlüğü’nden temin edilmiştir. Belirlenen ilçelerde araştırmaya dahil edilecek işletmelerin seçiminde tesadüfi örnekleme metodu kullanılmıştır. Buna göre, Battalgazi'de 23, Yeşilyurt'ta 11, Doğanşehir'de 23 ve Akçadağ’da 21 süt sığırcılığı işletmesi araştırma kapsamına alınmıştır. Araştırmada anketör olarak çalışacak kişiler konu hakkında özel olarak eğitime tabi tutulmuş ve bazı işletmelerde deneme amaçlı uygulamalar yapılmıştır. Daha sonra; ele alınacak tüm işletmeler bir takvime bağlı olarak ziyaret edilerek biyogüvenlik uygulamaları açısından önem gösteren bazı faktörlerin varlığı ve düzeyi bakımından yerinde incelemeler ve değerlendirmeler yapılmıştır. Araştırmada yapılan tespitler ve değerlendirmelerde, incelenen her bir parametrenin tüm işletmeler bazında sahip olduğu oransal değerler dikkate alınarak, biyogüvenlik uygulamaları açısından elde edilen oransal değerler; iyi/yeterli/yüksek (\%71 ve daha fazla), kabul edilebilir/orta (\%41-\%70) ve kötü/yetersiz/düşük (\%40 ve daha az) şeklinde sınıflandırılmıştır (13). Bu araştırmadaki anket soruları, bazı araştırmacılar tarafından süt sığırı yetiştiriciliği faaliyetinde bulunan işletmelerdeki biyogüvenlikle ilgili durumu değerlendirmek amacıyla yapılmış olan çalışmadan alınmıştır (14).

\section{İstatistiksel Analiz}

Araştırma sonunda elde edilen verilerin istatistiki analizlerinde SPSS programından yararlanılmış, her parametre için sayısal ve yüzde (\%) frekanslar hesaplanmıştır (15).

\section{BULGULAR}

Çalışmada, Malatya'daki süt sığırcılık işletmelerinde biyogüvenlik açısından gerekli bazı yapısal, donanımsal ve pratiksel faktörlerin durumu Tablo 1'de, biyogüvenlik açısından gerekli bazı personel faktörlerinin durumu Tablo 2 'de ve barınaklarda gerekli bazı donanımsal ve pratiksel faktörlerin durumu hakkında elde edilen sonuçlar Tablo 3'te verilmiştir. 
Tablo 1. Malatya'daki süt sığırcılık işletmelerinde biyogüvenlik açısından gerekli bazı yapısal, donanımsal ve pratiksel faktörlerin durumu.

Table 1. The status of some structural, equipping and practical factors required for biosecurity in dairy cattle farms in Malatya.

\begin{tabular}{lcc}
\hline İdare Binası & Frekans & Oran (\%) \\
Evet & 13 & 16.7 \\
Hayır & 65 & 83.3 \\
Toplam & 78 & 100 \\
Güvenlik Kamerası & Frekans & Oran (\%) \\
Evet & 14 & 17.9 \\
Hayır & 64 & 82.1 \\
Toplam & 78 & 100 \\
Işletme İçi Kayıt & Frekans & Oran (\%) \\
Evet & 52 & 66.7 \\
Hayır & 26 & 33.3 \\
Toplam & 78 & 100 \\
Dezenfektan Çukuru & Frekans & Oran (\%) \\
Evet & 24 & 30.8 \\
Hayır & 54 & 69.2 \\
Toplam & 78 & 100 \\
İşletme Etrafı Çevrili & Frekans & Oran (\%) \\
Evet & 55 & 70.5 \\
Hayır & 23 & 29.5 \\
Toplam & 78 & 100 \\
Farklı Türden Hayvanlar & Oran (\%) \\
Evet & 37.2 \\
Hayır & 29 & 62.8 \\
Toplam & 40 & 100 \\
\hline
\end{tabular}

Tablo 2. Malatya'daki süt sığırcılık işletmelerinde biyogüvenlik açısından gerekli bazı personel faktörlerinin durumu.

Table 2. The status of some staff factors required for biosecurity in dairy cattle farms in Malatya.

\begin{tabular}{lcc}
\hline Hizmet İçi Eğitim & Frekans & Oran (\%) \\
Evet & 13 & 16.7 \\
Hayır & 65 & 83.3 \\
Toplam & 78 & 100 \\
İşletmede Danışman & Frekans & Oran (\%) \\
Evet & 38 & 48.7 \\
Hayır & 40 & 51.3 \\
Toplam & 78 & 100 \\
İşci Portör Muayenesi & Frekans & Oran (\%) \\
Evet & 42 & 53.8 \\
Hayır & 36 & 46.2 \\
Toplam & 78 & 100 \\
İşçi Kıyafeti & Frekans \\
Evet & 68 & Oran (\%) \\
Hayır & 10 & 87.2 \\
Toplam & 78 & 12.8 \\
\hline
\end{tabular}


Tablo 3. Malatya'daki süt sığırcılık işletmelerinde biyogüvenlik açısından barınaklarda gerekli bazı donanımsal ve pratiksel faktörlerin durumu.

Table 3. The status of some equipping and practical factors in shelters for biosecurity in dairy cattle business in Malatya.

\begin{tabular}{lcc}
\hline Günlük Temizlik & Frekans & Oran (\%) \\
Evet & 70 & 89.7 \\
Hayır & 8 & 10.3 \\
Toplam & 78 & 100 \\
Havalandırma & Frekans & Oran (\%) \\
Evet & 72 & 92.3 \\
Hayır & 6 & 7.7 \\
Toplam & 78 & 100 \\
Otomatik Suluk & Frekans & Oran (\%) \\
Evet & 34 & 43.6 \\
Hayır & 44 & 56.4 \\
Toplam & 78 & 100 \\
Kaşıma Fırçası & Frekans & Oran (\%) \\
Evet & 45 & 57.7 \\
Hayır & 33 & 42.3 \\
Toplam & 78 & 100 \\
Izgaralı Kanal Sistemi & Orekans & 9.0 \\
Evet & 7 & 91.0 \\
Hayır & 71 & 100 \\
Toplam & 78 & 0 \\
\hline
\end{tabular}

\section{TARTIŞMA ve SONUÇ}

Yapılan çalışmada, idare binası ve güvenlik kamerası bulunan işletme oranları \%16.7 ve \%17.9 olarak belirlenmiştir. İşletmelerdeki tüm hareketlerin kontrolü ve düzeninin biyogüvenliğe uygun biçimde sağlanması için her işletmenin idare binasına sahip olması zorunludur. Güvenlik kameraları, hastalık etkenlerini işletmeye bulaştırabilecek ve farklı birimlere yayabilecek her türlü hareketin takibi ve kontrolü için gerekmektedir. Mevcut çalışmada idari bina ve güvenlik kameralarının varlığına ait belirlenen oranlar düşüktür. Her iki değer, işletme sahiplerinin idare binası oluşturma ve güvenlik kamerası kullanmada isteksiz olduklarını ve bunun önemini kavrayamadıklarını göstermektedir. Şanlıurfa'da yapılan bir araştırmada idare binası bulunan süt sığırcılığı işletmelerinin oranı \%41, güvenlik kamerasına sahip olanların oranı ise \%22 olarak belirlenmiştir (14).

Çiftlik kontrol listeleri, sütçü işletmelerde sürü sağlığı ve üretimle ilgili konuların takibini sağlayan bilgi kaynaklarıdır (16). Günümüzde ise hayvancılığı ilgilendiren tüm konuların takibinde yararlanılan gelişmiş bilgisayar programları bu amaçla kullanılmaktadır (17). Kayıtlar sayesinde biyogüvenliğe ilişkin işletmedeki eksikliklerin giderilmesi, geleceğin planlanması ve periyodik uygulamaların zamanında yapılması mümkün olabilmektedir. Mevcut araştırmada, işletme içi kayıt tutulan işletme oranı \%66.7 olarak tespit edilmiştir. Kayıt tutulmaması işletmeler için önemli bir eksikliktir. Şanlıurfa'da yapılan çalışmada işletme içi kayıt tutma oranı \%68 olarak bildirilmiştir (14). Malatya ve Şanlıurfa'daki işletmeler, kayıt tutma oranları bakımından birbirine oldukça yakın bulunmuştur.

İşletme girişlerinde, personel ve araçların muhtelif patojen mikroorganizmaları işletmeye sokmalarını engellemek için dezenfektan çukuru ve havuzu yapılmalı, içlerinde sürekli uygun bir dezenfektan bulundurulmalıdır. Sağımhane gibi biyogüvenlik bakımından kritik yerlerin girişlerine de 
mutlaka dezenfektan çukuru yapılmalıdır. Bu araştırmada dezenfektan çukuru/havuzu bulunan işletme oranı \%30.8'dir. Araştırmada tespit edilen bu düşük oran, işletmelere hastalık etkenlerinin bulaşması veya yayılması bakımından risk olduğunu göstermektedir. Şanlıurfa'da dezenfektan çukuru bulunan sütçü işletme oranı ise \%34 (14) olup, bu oran da Malatya'daki işletmelerde olduğu gibi son derece düşüktür.

İşletme etrafının çevrili olmaması, dışarıdan işletmeye kontrol dışı insan ve hayvan girişi, aynı zamanda çeşitli patojenlerin de işletmeye girmesi anlamına gelmektedir. Bu nedenle işletme etrafının uygun malzemelerle çevrilmesi, işletmelerin daha iyi kontrol edilebilmesini sağlamaktadır. Mevcut çalışmada etrafları çevrili olan işletmelerin oran \%70.5 olarak belirlenmiştir. Araştırmada tespit edilen bu oran, bazı işletmelerin dışarıdan giriş ve çıkışların yeterince kontrol edilmemesi nedeniyle bulaşıcı hastalıklara açık bir durumda olduklarını göstermektedir. Şanlıurfa'da ise etrafı çevrili olan işletmelerin oranı \%90'dır (14). Şanlıurfa'daki işletmeler bu bakımdan daha iyi bir duruma sahip olarak belirlenmiştir.

Sütçü işletmelerde farklı türden hayvanların bir arada bulundurulması önemli sakıncalar meydana getirmektedir. Yapılan çalışmada, tüm olumsuzluklara ve risklere rağmen Malatya'da farklı türden hayvanları bir arada bulunduran işletmelerin oranı \%37.2 olarak hesaplanmıştır. Bu oran yüksek bir değerdir. Bu nedenle optimum bir biyogüvenlik düzeyi sağlayabilmek için, işletmelerde değişik hayvan türlerinin bir arada bulundurulmaması gereklidir.

Değişen ve gelişen bilgilerin güncellenmesi, eski bilgilerin tazelenmesi bakımından hizmet içi eğitim, süt sığırcılığı yapan işletmeler için önemli konuların başında gelmektedir (18). Çalışan tüm personelin ve işletme sahiplerinin düzenli aralıklara hizmet içi eğitim alması, biyogüvenlik kurallarının daha etkin sürdürülmesini sağlamaktadır. Bu araştırmada, çalışanların hizmet içi eğitim aldıkları işletme oranı \%16.7 olarak belirlenmiştir. Şanlıurfa'da yapılan çalışmada ise buna ilişkin oran \%27.0 olarak bildirilmiştir (14). Malatya'da tespit edilen bu oran son derece düşük olup, işletmelerin hizmet içi eğitime gereken önemi vermedikleri anlaşılmaktadır. Oysa, başarılı ve karlı bir işletme için işletmede görevli tüm personelin belirli aralıklarla hizmet içi eğitimden geçirilmeleri önemlidir.

Hayvancılık işletmelerinde yetiştiricilerin sadece \%10'u biyogüvenlik konularında bilgiye sahiptirler. Bu nedenle, bilgi ve beceri bakımından yeterli düzeye ulaşmış veteriner hekimlerin işletmelere danışman olarak alınmaları gerekmektedir (19). Yapılan araştırmada, danışman çalıştıran işletmelerin oranı \%48.7 olarak hesaplanmıştır. Bu oran orta düzeyde bir değer olarak kabul edilebilir. Şanlıurfa'da yapılan çalışmada ise buna ilişkin oran \%60.0 olarak bildirilmiştir (14). Şanlıurfa İlindeki işletmelerden daha düşük bir orana sahip olan Malatya'daki işletmelerin danışman çalıştırmaya daha fazla önem vermeleri gerekmektedir.

İşletmelerde çalışanlar, hayvan sağlığı üzerinde doğrudan etkilidir (20). Portör muayeneleri, çeşitli hastalıkları subklinik olarak taşıyan personelin, varsa, ortaya çıkarılmasını sağlayan tıbbi uygulamalardır. Bu uygulama sayesinde hem hayvan sağlığı hem de insan sağlığı korunmuş olmaktadır. Bu çalışmada işçilere portör muayenesi yaptıran işletme oranı \%53.8 olarak belirlenmiştir. $\mathrm{Bu}$ oran, biyogüvenlik bakımından işletmelerdeki yetersizliği ve ciddi bir riskin varlığını açıkça ortaya koymaktadır. Şanlıurfa'daki süt sığırcılığı işletmelerinde ise portör muayenesi yapılan işletme oranı \%20.0 olarak bildirilmiştir (14). Bu bakımdan, Malatya'daki işletmelerin daha iyi durumda oldukları söylenebilir.

Biyogüvenlik kuralları gereğince işletme personelinin özel kıyafet giymesi, maske takması, el ve çizmelerini dezenfekte etmesi gerekmektedir. Personel dışında, farklı amaçlarla işletmeye gelenlerin farklı işletmelerde bulunmuş olmaları ve buralardaki hayvanlara temas etmiş olma ihtimalleri 
nedeniyle bu önlemler alınmalıdır. Yapılan çalışmada personele yapılacak işe mahsus kıyafet giydirilen işletme oranı \%87.2 olarak belirlenmiştir. Çalışmada elde edilen bu bulgu, bazı işletme yönetiminin hastalık etkenlerinin yayılmasını önleyici nitelikte ve biyogüvenlik kapsamındaki uygulamalar açısından önemli bir konu olan personelin yapacağı işin özelliklerine uygun kıyafet giydirilmesi noktasında gerekli hassasiyeti göstermediklerini ortaya koymuştur.

Hayvancılık işletmelerinde, hayvanların gezint ve dinlenme alanlarının temizlenme sıklığı ve etkinliğ zeminin kuru kalmasını sağlayarak enfeksiyonları azaltmaktadır (21). Biyogüvenlik bakımından genel olarak, barınak, depo, sağımhane gibi ünitelerle tüm ekipman ve malzemelerin düzenli biçimde temizlenip dezenfekte edilmesi gerekmektedir. Mevcut çalışmada, barınaklarda günlük temizlik yapılan işletme oranı \%89.7 olarak tespit edilmiştir. Tespit edilen bu yüksek oran, Malatya'daki bazı sütçü işletmelerin bu konudaki kısmi eksikliklerine rağmen, temizliğe yine de önem verildiğini göstermektedir.

Yapılan çalışmada, barınaklarda uygun ve yeterli havalandırma sağlanan işletme oranı \%92.3 olarak saptanmıştır. Yeterli havalandırma hayvanların temel bir ihtiyacı olduğu kadar işletmelerde hastalıkların oluşmaması için de gereklidir (22). Havalandırma hızı düşük olduğunda ortam havasındaki patojen mikroorganizmaların yoğunluğu, toz ve gübre gazlarının oranı artmaktadır. Böyle ortamlarda barındırılan hayvanlarda mastitis, solunum yolu hastalıkları ve verim kayıpları gibi olumsuzluklar meydana gelmektedir $(23,24)$. Ideal bir havalandırma, barınak tipi, büyüklüğü, barınaktaki hayvan sayısı ve mevsim gibi faktörlere bağlıdır (23). Genel bir kural olarak süt ineklerinde her 500 kg canlı ağırlık için havalandırma oranı kış aylarında 60 $\mathrm{m} 3 /$ saatten, yaz aylarında ise $300 \mathrm{m3} /$ saatten az olmamalıdır (25). Doğal havalandırma, daha az gürültü oluşturmasının yanında enerji tasarrufu sağlaması bakımından avantaj oluşturmaktadır (26).

Hayvan sağlığının korunması için hayvanlara içirilen sular, insanların içmesine elverişli suların kimyasal ve mikrobiyolojik kalitesinde olmalıdır (21). $\mathrm{Bu}$ nedenle, hayvanların sürekli temiz suya ulaşabilmeleri ve kontamine olmuş suları içerek hastalanmamaları için işletmelerde otomatik sulukların kullanılması tavsiye edilmektedir. Bu araştırmada otomatik suluk bulunduran işletmelerin oranı \%43.6 olarak saptanmıştır. Malatya'daki işletmelerde otomatik suluk kullanılması orta düzeylerde tespit edilmiş olup, kullanım oranlarının artırılması gerekmektedir. Şanlıurfa'daki sütçü işletmelerde ise otomatik suluk kullanım oranı \%78.0 olarak bildirilmiştir (14).

Hayvanların derileri ve kılları ahırdaki toz, toprak, kir, gübre ve ekto parazitler gibi unsurlar ile kirlenmiş olabilir. Bunları hayvanların üzerinden uzaklaştırmak için hayvanların günlük olarak düzenli biçimde tımar edilmesi gerekmektedir (27). Bu araştırmada, kaşıma fırçası bulunduran işletmelerin oranı \%57.7 olarak saptanmıştır. Şanlıurfa'daki sütçü işletmelerde ise kaşıma fırçası bulundurma oranı \%32.0 olarak bildirilmiştir (14). Bu verilere göre, Malatya'daki işletmelerde kaşıma fırçası kullanım oranı Şanlıurfa İlindeki işletmelerden daha yüksektir.

Bir süt ineği günde 9-16 kez defekasyon ve 4-10 kez de ürinasyon yapmakta (28-30), yıllık 8.000 kg süt veren bir inek günde $32 \mathrm{~kg}$ gübre ve $16 \mathrm{~kg}$ idrar çıkartmaktadır (31). Bukadar yoğun gübre ve idrar bulunan ortamlarda hastalık etkenleri son derece hızlı üremekte ve işletmenin farklı yerlerine yerleşmektedir. Bu nedenle; oluşan gübre, idrar ve zeminin yıkanmasıyla oluşan kirli suların birikip hayvanlara ve çevreye zarar vermesine müsaade edilmemelidir. Bu amaçla, ahır zeminindeki gübrenin bir bulamaç halinde rahatlıkla pompalanacağı ve taşınacağı bir ızgaralı kanal sistemi yapılmalıdır (21). Izgaralı kanal sistemleri, her türlü sıvının barınaklarda birikim yapmadan ortamdan uzaklaştırılmasını sağlayarak hastalıkları engellemektedir. Yapılan araştırmada ızgaralı kanal sistemine sahip işletmelerin oranı \%9.0'dur. Şanlıurfa'daki sütçü işletmelerde ise bu oran \%24.0'tür (14). Bu çalışmada, Malatya ilinde ızgaralı kanal sistemine 
sahip işletmelerin oranının son derece düşük düzeyde olduğu tespit edilmiştir.

Sonuç olarak, biyogüvenlik için gerekli bazı faktörler bakımından Malatya'daki süt sığırcılığı işletmelerinin \%71 ve daha fazlasında, işletmelerde günlük temizlik yapıldığı, yeterli havalandırma sağlandığı ve personele yapılacak işe mahsus kıyafet giydirildiği; \%41 ve daha fazlasında ise işletmelerin etrafının çevrili olduğu, hayvanlar için kaşıma fırçası kullanıldığı, işletme içi kayıt tutulduğu, otomatik suluk kullanıldığı, danışman çalıştırıldığı, farklı türden hayvanların bir arada bulundurulmadığı ve işçilere portör muayenesi yaptırıldığı tespit edilmiştir. Buna karşın işletmelerin \%40.0'ı ve daha azında ise, idare binasının olmadığı, güvenlik kamerasının bulunmadığı, dezenfektan çukuru kullanılmadığı, ızgaralı kanal sistemi olmadığı ve hizmet içi eğitim uygulamalarının yapılmadığı belirlenmiştir. Biyogüvenlik bakımından işletmelerin daha iyi bir düzeye erişilebilmesi için, belirlenen eksikliklerin ivedilikle düzeltilmesi gerekmektedir. Bu amaçla, öncelikle yetiştiriciler eğitilmeli ve bilinçlendirilmelidir. Bakanlık ilgili birimlerince işletmelerin daha sıkı denetlenmesi ve idari yaptırımların etkinleştirilmesi, başarılı işletmelerin örnek gösterilmesi ve taltif edilmesi önerilmektedir. Biyogüvenlik düzeyini etkileyen eksikliklerin giderilmesi sayesinde, Malatya'daki süt sığırcılığı işletmeleri daha sağlıklı bir yapıya kavuşacak, bu işletmelerde üretilerek tüketime sunulan hayvansal ürünlerin daha güvenilir biçimde tüketilmesi mümkün olacaktır.

\section{KAYNAKLAR}

1. Öziş Altınçekiç Ş., Koyuncu M., 2015. Küçükbaş hayvancılık işletmelerinde biyogüvenlik uygulamaları. Hay Üret, 56, 48-57.

2. Dijkhuizen AA., Morris RS., 1997. Animal health economics. Principles and applications. Post Graduate Foundation of Veterinary Science, University of Sydney, Sydney, Australia.

3. Kristensen E., Jakobsen EB., 2011. Challenging the myth of the irrational dairy farmer; understanding decision-making related to herd health. New Zeal Vet J, 59, 1-7.

4. Köseman A., Rişvanlı A., Kaygusuzoğlu E., Saat N., Korkmaz H., Şeker İ., 2015. Malatya ilindeki süt sığırcılık işletmelerinde yetiştiricilerin demografik özellikleri ve işletmedeki üreme, sürü sağlığı ve hijyen konularında bilgi düzeylerinin belirlenmesi. Avrasya Vet Bil Derg, 32, 101-108.

5. Anonim., 2013. Malatya il Gıda, Tarım ve Hayvancılık Müdürlüğü. Çalışma Raporu 2013.

6. Anonim., 2014. Tüik. 2014 Yılı Hayvancılık İstatistikleri.

7. Köseman A., Şeker I.,, 2016. Malatya ilinde sığırcılık işletmelerinin mevcut durumu: II. hayvan sağlığı ve ahır hijyeni perspektifinde biyogüvenlik uygulamaları. Kocatepe Vet Derg, 9, 61-69.

8. Cochran WG., 1977. Sampling Techniques. 3rd edition, 50-68, John Wiley \& Sons, NY, USA.

9. Sümbüloğlu K., Sümbüloğlu V., 2007. Biyoistatistik. 260-267, Hatipoğlu Yayınları, Ankara.

10. Savran F., 2003. Çanakkale damızlık süt sığırı yetiştirici birliğine üye olan ve olmayan işletmelerin kullandıkları üretim teknikleri ve sosyal karakteristiklerin karşılaştırılması. Tarım Bil Derg, 9, 450-453.

11. Demir P., Aral S., 2009. Kars ilinde faaliyet gösteren süt sığırcılık işletmelerinin karşılaştıkları sorunlar ve çözüm önerileri. Vet Hek Dern Derg, 80, 17-22.

12. Tugay A., Bakır G., 2009. Giresun yöresindeki süt sığırcılığı işletmelerinin yapısal özellikleri. Atatürk Üniv Zir Fak Derg, 40, 37-47.

13. Doğan Öi., Özdemir A, Akgündüz E., Kırda K., 2009. Dünya klasmanında üretim için performans kriterleri analizi, 9. Ulusal Üretim Araştırmaları Sempozyumu, 15-17 Ekim 2009, Osmangazi Üniversitesi, Eskişehir.

14. Yener H., Atalar B., Mundan D., 2013. Şanlıurfa ilindeki sığırcılık işletmelerinin biyogüvenlik ve hayvan refahı açısından değerlendirilmesi. Harran Üniv Vet Fak Derg, 2, 87-93.

15. SPSS 22.0, 2015. Statistical Package in Social 
Sciences for Windows. Chicago, USA.

16. Noordhuizen JP., Dobbelaar P., Wilbrink H., Ikink RW., 1983. The farm calendar, an aid in veterinary-zootechnical production and health policy of dairy farms. Tijdschr Diergeneeskd, 108, 895-903.

17. Dijkhuizen AA., Roosenschoon PL., Elving L., 1987. A stochastic computer simulation model for integrated zootechnical, veterinary and economic instruction regarding managerial decisions on dairy farms. Tijdschr Diergeneeskd, 112, 13291336.

18. Hall J., Wapenaar W., 2012. Opinions and practices of veterinarians and dairy farmers towards herd health management in the UK. Vet Rec, 28, 170, 441.

19. Laanen M., Maes D., Hendriksen C., Gelaude P., De Vliegher S., Rosseel Y., Dewulf J., 2014. Pig, cattle and poultry farmers with a known interest in research have comparable perspectives on disease prevention and on-farm biosecurity. Prevent Vet Med, 115, 1-9.

20. Seabrook MF., Bartle NC., 1992. Human factors. In: Phillips, C. and Piggins, D., Farm animals and the environment, 111-125, CAB International, Oxon.

21. Scientific Report of Efsa, 2009. Scientific report on the effects of farming systems on dairy cow welfare and disease. Report of the Panel on Animal Health and Welfare, (Question No EFSAQ-2006-113).

22. Pelzer A., 1998. Environmental control in cattle housing. Milchpraxis, 36, 70-74.

23. Wathes CM., 1992. Ventilation. In "Farm animals and the environment". Phillips C Piggins D (eds)., 83- 89, CAB International, Oxon.

24. Novak P., Vokralova J., Knizkova I., Kunc P., 2005. Welfare conditions of dairy cows from the point of performance efficiency. Animals and Environment, 1, 118-123.

25. Herkner S., Lankow C., Heidenreich T., Panzer K., 2002. Minimum summer ventilation flow for high performance dairy cattle. Landtechnik, 57, 286-
287.

26. Kiwan A., Berg W., Brunsch R., Özcan S., Müller HJ., Glaser M., Fiedler M., Ammon C., Berckmans D., 2012. Tracer gas technique, air velocity measurement and natural ventilation method for estimating ventilation rates through naturally ventilated barns. Agric Eng Int: CIGR Journal, 14, 22.

27. Hultgren J., 2001. Observational and experimental studies of the influence of housing factors on the behaviour and health of dairy cows. Doctoral thesis. Swedish University of Agricultural Sciences, Uppsala.

28. Sahara D., Ichikawa T., Aihara Y., Kawanishi H., Nagashima M., 1990. Eliminative and reposing behaviour of dairy cows in the stanchion stall barn. Japanese Jour Zootech Sci, 61, 249-254.

29. Phillips CJC., 1993. Cattle Behaviour, 212, Farming Press Books, Ipswich.

30. Aland A., Lidfors L., Ekesbo I., 2002. Diurnal distribution of dairy cow defecation and urination. Appl Anim Behav Sci, 78, 43-54.

31. Swensson C., Gustafsson G., 2002. Characterization of influence of manure handling system and feeding on the level of ammonia release using a simple method in cow houses. Anim Sci, 52, 49-56. 